\title{
O ENSINO DA MÚSICA PARA PESSOAS COM DEFICIÊNCIA: RELATOS E REFLEXÕES EM TORNO DE UM ACONTECIMENTO EDUCATIVO
}

\author{
Apoliana Regina Groff ${ }^{i}$ \\ Ana Paula Evaristo Russii \\ Josiele Bené Lahorgue $\mathrm{iii}^{\mathrm{ii}}$
}

\section{Resumo}

Este trabalho se constitui de relatos e reflexões em torno de um acontecimento educativo, construído com estudantes de uma instituição que oferece atendimentos educacionais a pessoas com deficiência. O contexto deste acontecimento diz respeito à disciplina de Artes e, mais especificamente, ao ensino da música. Foi a partir da introdução dos/as educandos/as à linguagem musical, da composição de letras, arranjos e da gravação de um CD que o ensino da música aconteceu. Reflete-se sobre a construção do acontecimento educativo e os processos de criação envolvidos, sobre o ensino da música na Educação Especial, bem como, acerca do querer a experiência na educação como uma responsabilidade ética do/a educador/a.

Palavras-chaves: Música, Pessoas com Deficiência, Acontecimento Educativo, Experiência.

\begin{abstract}
This work consists of reports and reflections on an educational event, built with students from an institution that provides educational services provided to people with disabilities. The context of this event concerns the discipline of Arts and, more specifically, music teaching. Music education happened from the introduction of students to the musical language of the composition of lyrics, arrangements and recording a CD. We reflected on the production of an educational event and the creative processes involved, on the music education in Special Education, and about wanting the experience in education as an ethical responsibility of the educator.
\end{abstract}

Keywords: Music; People with Disabilities; Educational Event; Experience.

\section{Introdução}

Este trabalho apresenta relatos em torno do ensino da música em uma instituição de Educação Especial que atendia pessoas com deficiência. O ensino da música na Educação Básica, apesar de sua obrigatoriedade desde 2008 de acordo com a lei 11769, ainda não se efetivou de 
forma ampla no Brasil. Trata-se, portanto, de um processo longo em que, no caso específico da Educação Especial, como uma modalidade de ensino, os desafios são ainda maiores e mais complexos. O ensino da música, de modo geral na escolarização de crianças e adolescentes, tem vivenciado um momento de experimentação, de criação de estratégias pedagógicas e de troca de saberes e modos de fazer entre os/as educadores/as.

Este artigo se propõe, então, a socializar o que se denominou como um acontecimento educativo envolvendo o ensino da música para pessoas com deficiência. Tal acontecimento foi construído junto aos/as educandos/as, levando em conta as suas múltiplas realidades e potencialidades criadoras, bem como o fazer inventivo e sensível da professora de música, o que resultou na gravação de um CD intitulado "Máscaras, Versos e Risadas" (2010) ${ }^{\mathrm{i}}$. Os processos de composição e elaboração dos arranjos musicais e a gravação das músicas serão relatados com mais detalhes no decorrer do texto.

A proposta aqui é também olhar para este acontecimento educativo, refletindo sobre ele a partir de algumas condições de possibilidade do ensino da música na Educação Especial, demarcando um contraponto a modos de relação estigmatizantes e excludentes que instituem $a$ priori o que os corpos com deficiência podem ou devem fazer, fundamentados em uma suposta normalidade, bem como posicionar o lugar do/a educador/a como aquele/a que deseja a experiência na educação (LARROSA, 2002, 2009).

\section{Sobre a Instituição}

No ano de 2010, uma das autoras deste texto, que é professora de música, foi contratada por uma instituição de Educação Especial, localizada na região do Vale do Itajaí em Santa Catarina, para compor o quadro de professores/as da disciplina de Artes. Neste período, a disciplina contou com um professor de Artes Visuais e com a professora de Música. Nos 25 anos de existência da instituição, esta foi a segunda vez em que a mesma contou com a presença de um/a educador/a musical no corpo docente, já que a formação em música não é uma exigência para a docência na referida disciplina.

A disciplina de Artes era trabalhada nesta instituição nos seguintes programas de atendimento: Serviço de Atendimento Educacional Especializado - SAEDE: prestava auxílio pedagógico a crianças e adolescentes que frequentavam a escola regular, no período do contraturno; Oficinas Pedagógicas: eram dirigidas a adultos com deficiência intelectual de baixo e médio grau e propunham a educação para o trabalho, através de atividades de fabricação de estopas e confecção de artigos de papel reciclado; Serviço Pedagógico Específico - SPE: atendia 
crianças e adolescentes com deficiência caracterizada por alto comprometimento cognitivo; Transtornos Invasivos de Desenvolvimento - TID: previa o atendimento de crianças e adolescentes com autismo, Síndrome de Asperger e Transtorno de Hiperatividade associado a déficit cognitivo; Ocupacionais: a esta modalidade eram direcionados os adultos com deficiência de alto comprometimento cognitivo ${ }^{\mathrm{v}}$.

Estes programas atendiam a cerca de 200 educandos/as, com idades entre 6 e 58 anos; portanto, a organização dos mesmos se caracterizava desde uma divisão em faixas etárias - turmas de crianças, adolescentes e adultos - e desde suas possibilidades em frequentar a escola regular ou trabalhar. Assim, apenas crianças e adolescentes do SAEDE eram considerados aptos/as a frequentar a escola e somente os adultos das Oficinas Pedagógicas eram designados capazes de acessar o mercado de trabalho. Os/As demais educandos/as, em geral, ficavam restritos à instituição e às suas residências e, na melhor das hipóteses, a seus bairros. Na maior parte dos casos, educandos/as do SPE, TID e Ocupacionais, para conviver em outros espaços, dependiam da iniciativa de seus familiares e/ou responsáveis ou dos passeios promovidos pela instituição, os quais muitas vezes eram restritos aos integrantes das Oficinas Pedagógicas, que se constituíam no único programa que gerava renda para financiar as atividades extra-institucionais de seus participantes.

No caso do ensino de música, a educadora desenvolveu um trabalho de introdução à linguagem musical, de composição e criação de músicas com educandos/as dos cinco programas descritos acima. Cada programa contava com mais de uma turma de educandos/as, as quais agrupavam entre duas e quinze pessoas. Alguns participantes apresentavam cegueira, baixa visão, surdez, distúrbios da fala e/ou dificuldades motoras de níveis diversos associados ao diagnóstico de deficiência intelectual. Assim, a proposta pedagógica do ensino da música aconteceu de forma diferenciada em cada turma, tendo em vista as condições coletivas e individuais, no que diz respeito, por exemplo, à necessidade de adaptação de alguns instrumentos, a motivação dos/as educandos/as, os limites e possibilidades da própria educadora.

\section{O Ensino da Música na Educação Especial}

Dentre os marcos da história da Educação Especial no âmbito internacional, destaca-se a Declaração de Salamanca - resolução adotada na Assembleia Geral das Nações Unidas em 1994 - que versa sobre a universalização da escola regular a todas as crianças, "independentemente de suas condições físicas, intelectuais, sociais, emocionais, linguísticas ou outras” (ONU, 1994, p. 3). 
Assim, o que esta Declaração propunha, já na década de 1990, era uma perspectiva de inclusão de todos e de todas na educação.

Passados mais de 20 anos, muitos foram os aparatos jurídicos criados no sentido de estabelecer uma política de inclusão de todos/as nas escolas brasileiras, mas também, legislações e documentos que versam sobre a Educação Especial, como é o caso da Lei de Diretrizes e Bases da Educação Nacional (LDB) de 1996; das Diretrizes Nacionais para a Educação Especial na Educação Básica de 2001; da Política de Educação Especial na Perspectiva da Educação Inclusiva de 2007/2008 e; do Decreto n ${ }^{\circ}$ 7611/2011 que dispõe sobre a Educação Especial e o Atendimento Educacional Especializado para "pessoas com deficiência, com transtornos globais do desenvolvimento e com altas habilidades ou superdotação” (BRASIL, 2011, s/p), preferencialmente no ensino regular.

Beyer (2007) salienta que, se no passado as escolas especiais tiveram seu papel de promover a integração, abrindo as portas do sistema educacional às pessoas com deficiência, hoje esse papel já não lhe cabe, pois agora o desejo é que essas pessoas possam frequentar a educação regular e nela receberem a assistência necessária e garantia do direito à educação. No entanto, o desenlace desse processo é longo e oneroso, encerrando em si mesmo resistências, dificuldades, como também, abrindo novas questões no âmbito da inclusão na educação. Isso fica claro quando Skliar (2011a, 2015) e outros/a autores/as (VEIGA-NETO;LOPES, 2011) problematizam, por exemplo, o próprio paradigma da normalidade e a invenção dos anormais; a produção dos diferentes a serem incluídos; o uso imperativo e naturalizado da palavra inclusão que engendram práticas carregadas de exclusão e humilhação; a falta de acompanhamento das políticas e projetos de inclusão; entre outras questões.

Nesta direção, se há no Brasil e no mundo um amplo e adequado discurso jurídico em torno da inclusão de todos/as na escola e do direito à educação das pessoas com deficiência, sabe-se que a realidade vivida por estas pessoas no que diz respeito às condições concretas de efetivação deste direito ainda são preocupantes. Segundo dados presentes no informe da Organização das Nações Unidas (ONU) de 2006 sobre o direito à educação de pessoas com deficiência em países da América Latina, apenas entre 1 e $5 \%$ destas pessoas em idade escolar estão efetivamente inseridas no sistema educacional (SKLIAR, 2015).

Quando se olha para o contexto dos/as educandos/as atendidos pelos programas da instituição descrita anteriormente, pode-se observar que muitas crianças e adolescentes em idade escolar não frequentavam o ensino regular, sobretudo, aqueles/as com comprometimento cognitivo acentuado. Se por um lado o direito à educação destes sujeitos está garantido nesta instituição, por outro, parecem existir critérios que ainda excluem algumas pessoas com 


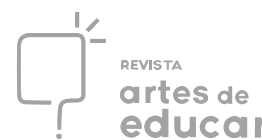

deficiência do sistema regular. Esta ainda é uma questão complexa que envolve aspectos práticos, técnicos e políticos, mas, sobretudo, aspectos éticos acerca da disponibilidade e da responsabilidade com cada pessoa com deficiência que está dentro e fora da escola (SKLIAR, 2015).

Da mesma forma que no plano jurídico há conquistas e avanços em relação ao direito à educação das pessoas com deficiência, o ensino da música vive uma realidade parecida, enfrentando desafios diretamente ligados à perspectiva da inclusão de todos/as os/as educandos/as na Educação Básica. Isso porque, embora a educação musical seja historicamente uma prática do currículo escolar que permaneceu informalmente em algumas instituições regulares, ela formalmente passou a integrar o sistema de ensino a partir da Lei $\mathrm{n}^{\mathrm{o}} 11.769$ de 2008 , que trata da obrigatoriedade do ensino de música na Educação Básica.

Desde então, muitos são os diálogos acerca da maneira como fazer a inserção dessa linguagem artística na educação, o que tem se constituído, segundo Kleber e Palma (2010), em um debate extenso que perpassa por questões delicadas, algumas levantadas pela Associação Brasileira de Educação Musical (ABEM) e pelo Instituto Arte na escola, tais como: o que significa a música integrar a matriz curricular de Artes, até então ministrada predominantemente por professores/as da área de Artes Visuais? Como organizar o currículo de música de forma que dialogue com a realidade escolar? Como estabelecer programas que fomentem a formação de professores/as de música?

Esse debate de âmbito nacional demonstra o quanto a educação musical nas escolas se constitui em um terreno de experimentação - fato que é salientado pela disparidade de oferta da disciplina na educação pública: enquanto muitos municípios já contrataram professores de música e estão definindo o lugar desta na Educação Básica, outros sequer têm definida esta linguagem dentro do currículo de Artes, ainda que o prazo para adaptação às exigências da referida lei tenha expirado em 2011.

Esse cenário é reforçado por levantamentos recentes desenvolvidos em diversas regiões do Brasil. Um deles, realizado na cidade de Belém do Pará, apontou um número insuficiente de educadores/as musicais, problemas estruturais e inadaptação da grade curricular nas escolas (FAÇANHA, 2014). Uma outra pesquisa nas escolas da região litorânea do Rio Grande do Sul apontou que apenas $29 \%$ dos municípios têm educadores/as musicais disponíveis para todas as unidades de ensino (SILVA, 2014). Diante do panorama de implantação da educação musical na educação regular, pode-se presumir que nas demais modalidades da Educação Básica - onde se inclui a Educação Especial - a estratégia ainda é frágil ou inexistente. Ao mesmo tempo, apesar dos muitos debates que anteciparam a promulgação da Lei $\mathrm{n}^{\circ} 11.769$, o momento atual da 


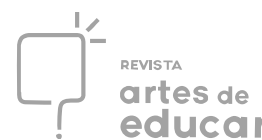

Educação Musical no Brasil pode ser entendido como de intensa troca de vivências e de busca por pedagogias que migrem de forma responsável da teoria para a práxis em todos os âmbitos da educação.

Neste aspecto, o ensino da música para pessoas com deficiência é um trabalho desafiador para o/a educador/a musical, tanto no contexto da inclusão nas escolas como nas instituições de Educação Especial. Os fazeres que constituíram o trabalho a ser descrito neste artigo incorporaram, deste modo, o caráter de experimentação de uma proposta pedagógica que se constrói no próprio espaço educacional, como também enquanto aprendizagem coletiva. Ou seja, a partir do fazer musical, todos são convidados a atuar e criar, pois a finalidade é a música em si, entendendo-a "como uma das várias atividades humanas, como uma dimensão fundamental da cultura, algo que permeia a vida de seus alunos, tanto na escola como fora dela" (HENTSCHKE; DEL BEN, 2003, p. 183).

Refere-se a "música em si”, pois o ensino da música e as aprendizagens possíveis a partir dela, dizem respeito ao que pode acontecer neste encontro tanto ao/a educador/a como ao/à educando/a, sendo que a música é entendida como uma linguagem artística fundamental para o desenvolvimento social, cultural e criativo dos/as estudantes, e não como um adereço no currículo da Educação Básica, incluindo suas modalidades de ensino. Importante demarcar, neste sentido, que "através da arte construímos relações com o saber: saber de nós mesmos, saber dos outros, saber das coisas e do mundo", bem como produzimos "elementos de estranhamento surgidos nas práticas e vivências realizadas em sala de aula, o que pode servir de mote para questionamentos e reflexões individuais ou coletivas" (ZAMPERETTI, 2015, p. 82).

Entende-se que é possível pensar nessa linguagem artística como algo que pode expressar a multiplicidade presente dentro de uma instituição de Educação Especial, abrangendo as potencialidades dos/as educandos/as e compondo um acontecimento educativo singular no qual eles/as possam, artisticamente, falar de si mesmos, da instituição, da comunidade ou mesmo praticar a expressão livre, descompromissada com o sentido formal da linguagem. Nesta direção é que o acontecimento educativo, a ser relatado no que segue, foi construído.

\section{Compondo um Acontecimento Educativo}

O que se denominou aqui de acontecimento educativo, diz respeito a todo um processo envolvendo o ensino da música para pessoas com deficiência, construído no sentido de dar condições para que os/as educandos/as fossem introduzidos à linguagem musical a partir do interesse e da possibilidade de cada um e de cada uma e da experimentação de estratégias 
pedagógicas. Existia o entendimento, desde o início, de que o processo de criação humano é contextual e infinito e que a partir dele, o sujeito se apropria de conhecimentos e técnicas já (re)criados para (re)criá-los novamente, resultando em um amálgama no qual estão em jogo experiências passadas, evidências presentes e perspectivas futuras (BAKHTIN, 2011).

Neste sentido, havia uma aposta, por parte da educadora, de que o ensino da música engendraria processos de criação e aprendizagens significativas tanto para ela como para os/as educandos/as. Por parte destes/as, percebeu-se um forte elo com o cotidiano da instituição, assim como a vivência com suas famílias e outros aspectos proeminentes de suas vidas como o contato com a televisão e com a linguagem musical. $\mathrm{Na}$ expressividade diária, os/as educandos/as expunham essa perceptividade com relação ao que os/as rodeava. A vontade de externalizar o que percebiam foi a primeira característica admitida como possibilidade para a expressão através do ensino da música.

Assim, trabalhou-se com propostas pedagógicas que pudessem aproveitar o interesse dos/as discentes pelo aprendizado musical, abrindo espaço para o reconhecimento dessa linguagem, lançando mão de uma série de adaptações para os/as educandos/as com dificuldades motoras, como prender instrumentos às cadeiras de roda, colocar alças nas baquetas para prendêlas às mãos, usar caixas de ressonância maiores para ampliar sons e utilizar braçadeiras com guizos, ponteiras, manoplas, entre outros.

No caso de educandos/as com dificuldades na fala, utilizou-se boccachiusa, um recurso de técnica vocal que consiste em cantar frases melódicas com a boca fechada, propiciando assim que os/as estudantes que não possuíam a oralidade conseguissem participar das canções. Para aqueles/as com deficiências intelectuais avançadas, foram propostas atividades simples de percussão corporal, andamentos mais lentos, frases melódicas curtas e versos simplificados. Com estes recursos preparados, durante dois meses trabalhou-se ritmo, canto e manuseio de instrumentos de percussão. Constatou-se que eles/as mostravam disposição e interesse na realização das atividades, em especial nas de natureza rítmica, de improviso e criação principalmente quando nas toadas havia referência a eles próprios.

Estas propostas pedagógicas visaram, sobretudo, a experimentação sonora adequada às possibilidades de cada educando/a. Trabalharam-se atividades diversas, desde o simples manuseio, extraindo sons de cada instrumento de forma espontânea, como também através de jogos envolvendo aspectos rítmicos - como a brincadeira Escravos de Jó, emprego de ostinatos ${ }^{\mathrm{vi}}$ (em alguns casos), e o acompanhamento rítmico de músicas escolhidas pelos/as próprios/as educandos/as. Nas atividades de canto, se envolveu músicas do cotidiano dos/as discentes e toadas populares, abordando aspectos como intensidade e andamento. Algumas destas atividades se 
repetiram ao longo de todo o processo de composição, permitindo que os/as aprendizes chegassem à fase de gravação familiarizados/as com os instrumentos e, em alguns casos, preparados/as para propor e realizar células rítmicas simples.

Durante o processo de familiarização com a linguagem musical, também foi proposto aos/às estudantes a composição da letra de uma canção. Em alguns casos, por se tratar de sujeitos que reconheciam parcialmente ou não identificavam a forma verbal de comunicação, utilizou-se outras estratégias para tal fim. Cabe esclarecer que o trabalho de composição ocorreu de forma diferenciada em cada turma e que a gravação do $\mathrm{CD}$ aconteceu após três meses de trabalho junto aos/às educandos/as.

No caso de uma das turmas do programa Oficina, foi sugerido aos/às discentes que escolhessem um assunto sobre o qual gostariam de compor. Eles/as selecionaram o tema "amor" e, através do diálogo, expressaram suas opiniões a respeito. Registrou-se por escrito as falas, as quais foram organizadas em conjunto, resultando na seguinte composição:

Amor é paixão / Me faz lembrar aquela música / Quero te namorar / Estou apaixonado / Tenho vontade de cantar / Estou feliz de amor / Amor me traz felicidade / Eu e você / Juntos nesta canção / Eu amo alguém / Estou muito apaixonado / Vamos sorrir / Amor nos deixa muito feliz. ${ }^{\text {vii }}$

Com a turma do SAEDE, trabalhou-se com a proposta de contar uma história, que resultou na seguinte composição:

Boi, boi, boi, boi, / Boi, boi, boi, boi, / Boi, boi, boi, boi, / Boi, boi, boi, boi. / O boizinho da Natacha, / quando era bebezinho, / tinha uma roupa bonita / que deixava ele azulzinho. / Bebê, bebê, / Bebê, bebê, / Bebê, bebê, / Bebê, bebê. / Era um bicho tão pequeno, / mas com poderoso berro. / Depois que virou adulto / só vestia amarelo. / $\mathrm{Mu}, \mathrm{mu}, \mathrm{mu}, \mathrm{mu}, / \mathrm{Mu}, \mathrm{mu}, \mathrm{mu}, \mathrm{mu}, / \mathrm{Mu}, \mathrm{mu}, \mathrm{mu}, \mathrm{mu}$, / $\mathrm{Mu}, \mathrm{mu}, \mathrm{mu}, \mathrm{mu}$. / Era pra trocar de cor / o boizinho quando velho, / Mas Natacha não deixou / e ele continuou... / Como ficou o boizinho, Natacha? / Amarelo!

Aqui cabe ressaltar que o andamento da história está exatamente de acordo com o que foi proposto por uma educanda cuja fala é monossilábica - isto é, pronunciava apenas palavras curtas, como boi, pai, "zul" (azul). A saga do personagem corresponde aos rumos por ela decididos e a repetição das interjeições mu, bebê e boi, reflete a característica de repetição da sua fala.

Nos programas do TID e Ocupacional, estimulou-se os grupos a buscarem elementos que chamavam a atenção destes na vida escolar. O primeiro apontou um colega que sempre pedia para "ir pra casa"; o segundo, um colega que frequentemente dormia durante as aulas. Foi feito o 
registro das falas dos/as educandos/as, bem como, se sugeriu algumas frases. A composição do TID ficou assim:

Acorda, Aparício / Não é hora de cochilar / Assim é difícil / Você precisa nos acompanhar / Acorda, Aparício / Que a aula já vai começar. viii

E a composição de uma turma do programa Ocupacional ficou da seguinte forma:

Almir, não vá embora / Almir, não vá embora / Ainda não é hora de ir pra casa. ${ }^{\text {ix }}$

Em outro grupo do Ocupacional, colocou-se os/as educandos/as frente ao microfone para captar suas expressões e falas espontâneas. Muitos/as tinham limitações no desenvolvimento linguístico, apresentando falas estereotipadas, as quais diariamente compunham a paisagem sonora dos corredores da instituição, motivo que impulsionou os registros. Repetiu-se o procedimento com as turmas do SPE e o resultado foi a canção SPECCOncept (resultante das siglas SPE e CCO, ou Centro de Convivência Ocupacional, como era chamado antigamente o programa Ocupacional).

Alô / Alô, garotada / Dá beijinho / Mamãe / Felicidade / Ieda / Já comeu? / Dá beijo / Não mexe / Bota outro. ${ }^{\mathrm{x}}$

Concomitante ao processo de composição das letras foi-se delineando o arranjo das músicas (vocais e harmonia). Utilizando um violão, foram incluídas sugestões melódicas e rítmicas dadas pelos/as estudantes - que cantarolavam suas ideias - e outras variantes, que eram acrescentadas de acordo com suas impressões. Em outros casos, o arranjo era feito ao mesmo tempo do surgimento dos versos, utilizando o mesmo processo de diálogo e sugestão dos/as educandos/as. Houve ainda situações em que o arranjo ficou a cargo da professora.

As composições musicais surtiram efeitos positivos nos/as estudantes: eles/as se mostraram eufóricos/as e orgulhosos/as pela possibilidade de cantar e tocar algo produzido por eles/as mesmos/as. Com base nisso, e sabendo que a instituição possuía a maior parte dos equipamentos sonoros adequados, pensou-se em registrar essas canções. Essa proposta de poder levar as canções criadas pelos/as educandos/as registradas em CD, para que pudessem recordar e mostrar aos familiares suas criações, foi muito bem recebida por eles/as.

No processo de gravação, os/as discentes contribuíram com suas vozes (que foram gravadas individualmente ou em coro), e tocando instrumentos de percussão (tambor, agogô, recoreco, prato, triângulo, pau-de-chuva, guizo, caxixi). A colaboração da professora de música nos registros consistiu no uso do canto como guia e no acréscimo de instrumentos como teclado e 
violão (para agregar harmonia, linhas melódicas e efeitos sonoros). Também nesta etapa, aproveitou-se ao máximo alguns conhecimentos musicais prévios dos/as educandos/as, permitindo novamente que os mesmos contribuíssem nos aspectos de arranjo. Foi o caso de um estudante da Oficina que praticava o beatbox (percussão vocal).

A fase de edição do $\mathrm{CD}$ não contou com a participação dos/as discentes por exigir um conhecimento técnico mais específico. Basicamente, realizou-se a sincronização das gravações, o acréscimo de efeitos simples e a mixagem (junção das gravações em uma única faixa), descartando de antemão recursos que pudessem alterar a identificação da voz, como afinadores eletrônicos, evitando encobrir ou distorcer o produto criativo dos/as educandos/as.

Nesses processos de criação, procurou-se estimular e perceber a expressividade de todos/as, através de sorrisos, balbucios e outros sinais, tendo em vista que nem todos/as os/as educandos/as conseguiam se comunicar oralmente. Também se buscou oferecer recursos para que os/as educandos/as pudessem participar tanto das composições como da execução, motivo pelo qual foram utilizadas adaptações para o manuseio dos instrumentos, a técnica da boccachiusa, bem como a percussão corporal. Tais propostas referem-se à percepção das potencialidades de cada educando/a, buscando criar condições para que as mesmas pudessem emergir no processo criativo, possibilitando assim que os sujeitos recriassem suas próprias existências.

Nesta direção, entende-se que o ato criador artístico não é um ato místico ou característica de apenas algumas pessoas, mas tão real quanto todos os outros atos humanos. Segundo Vygotski (1999, p. 325), "ensinar o ato criador da arte é impossível; entretanto, isso não significa, em absoluto, que o educador não pode contribuir para a sua formação e manifestação". Neste sentido é que se faz necessária a construção de um acontecimento educativo no ensino da música na Educação Especial, que leve em conta a realidade dos/as educandos/as, suas aprendizagens prévias, suas condições de acesso e uso dos instrumentos, a técnica e os saberes do/a professor/a, como também, o devir dos corpos e a potência daquilo que se pode construir junto com o outro. $\mathrm{O}$ processo criativo existente neste trabalho consolidou-se, portanto, a partir da percepção da professora e das possibilidades dos/as educandos/as de (re)criarem e transcenderem a própria realidade (ZANELLA, 2007).

Tal qual Wazlawick (2010) descreve em sua pesquisa com um duo de violões, as produções musicais engendradas neste acontecimento educativo caracterizam um ato de criação conjunta, através da relação dialógica entre a professora e os/as educandos/as - relação que se estabeleceu com a garantia da compreensão e da comunicação entre as partes envolvidas. Percebeu-se, portanto, “[...]a música e seu processo de criação como uma construção dialógica entre as várias 
vozes musicais presentes na história de um sujeito entremeadas ao processo de criação da própria vida" (WAZLAWICK, 2010, p. 256).

Por relações dialógicas entendemos as relações de tensão existentes entre as diversas vozes sociais que compõem o universo de (im)possibilidades presentes nas relações entre professora e educandos/as. Sendo assim, a relação dialógica é essencial no processo de criação, pois possibilita que as tensões entre os sujeitos sejam evidentes e importantes nesse processo, pois cada qual apresenta sua perspectiva que, no conjunto, se justapõe para a composição desse acontecimento educativo. Assim, sob a perspectiva dialógica, o processo criativo se estabeleceu através das tensões entre os sujeitos e suas criações, bem como das diversas vozes sociais em (des)compasso, modificando a si mesmos e ao grupo.

O processo criativo, tal qual o processo necessário a construção de um acontecimento educativo, constitui-se a partir das relações dialógicas estabelecidas entre os sujeitos envolvidos nos mesmos. Relações estas que "podem levar a direções imprevistas no que se refere à constituição de seus próprios sujeitos" (ZANELLA, 2007, p. 152), já que estes se compõem na partitura da vida e, seus (des)compassos, possibilitam a expressão de sujeitos sempre em devir.

\section{Querer a Experiência na Educação}

Olhar para os relatos e reflexões tramados até aqui, implica em uma abertura a outros sentidos provocados pelo acontecimento educativo que envolveu o ensino da música para pessoas com deficiência. Uma abertura capaz de problematizar algumas dimensões da Educação Especial e do ensino da música neste contexto, bem como o lugar do/a educador/a como aquele que deseja a experiência, ou seja, como aquele que vislumbra que algo aconteça na sua vida e na vida dos/as educandos/as a partir da composição de um acontecimento educativo.

A forma como o conceito de experiência é colocado em cena neste texto se ancora na compreensão de que a experiência tem a ver com aquilo que acontece a um sujeito, com aquilo que o afeta deixando vestígios nos seus modos de pensar, sentir, agir (LARROSA, 2009). A experiência, neste sentido, afeta de modo singular e produz ressonâncias; ela não só forma como transforma os sujeitos. Contudo, não se pode falar da experiência do outro, pois o lugar da experiência é o corpo e a existência de cada um e de cada uma.

Deste modo, se a experiência é o que acontece a um sujeito, "duas pessoas, ainda que enfrentem o mesmo acontecimento, não fazem a mesma experiência. $\mathrm{O}$ acontecimento é comum, mas a experiência é para cada qual sua, singular e de alguma maneira impossível de ser repetida" (LARROSA, 2002, p. 27). Criar condições para que uma experiência possa existir, ou seja, querer 
que algo afete os/as educandos/as, dependerá então, também do lugar do/a educador/a e do modo como ele constrói a relação educativa como um acontecimento. Não se pode, nestes termos, oferecer uma experiência ao outro, mas é possível querer a experiência e criar algumas condições para que algo possa vir a acontecer na vida dos/as educandos/as.

Nesta direção, Larrosa (2002) inspira aqueles/as educadores/as que querem a experiência, ao apontar alguns movimentos de paragem para que algo possa tocar os sujeitos:

(...) parar para pensar, parar para olhar, parar para escutar, pensar mais devagar, olhar mais devagar, e escutar mais devagar; parar para sentir, sentir mais devagar, demorar-se nos detalhes, suspender a opinião, suspender o juízo, suspender a vontade, suspender o automatismo da ação, cultivar a atenção e a delicadeza, abrir os olhos e os ouvidos, falar sobre o que nos acontece, aprender a lentidão, escutar aos outros, cultivar a arte do encontro, calar muito, ter paciência e dar-se tempo e espaço (LARROSA, 2002, p. 24).

Ou seja, querer a experiência numa relação educativa, e convidar o outro para que embarque nesta possibilidade requer a desnaturalização e um deslocamento dos modos de vida agenciados pela pressa, pela mesmidade, pelo tempo cronológico, pelos olhares indiferentes, pela crudeza com que as coisas passam sem deixar vestígios nas relações educativas. Requer, também, a interrupção e desconstrução de olhares e linguagens educativas binárias que arrebatam os corpos como normais e anormais e que determinam o que eles podem ou não podem. Querer a experiência na educação e, sobretudo, na Educação Especial, implica em uma disposição para criar acontecimentos educativos que fogem do transcendentalismo, finalismo, salvacionismo, prescritivismo e messianismo presentes no pensamento pedagógico moderno (VEIGA-NETO, 2005); criar acontecimentos que escapem do dever ser, do certo e do errado, do normal/anormal, das respostas rápidas, da vontade de verdade sobre o outro.

Nas reflexões relativas ao ensino da música na Educação Especial, há que se problematizar também que esta, "é antes de tudo a fabricação de um conjunto de dispositivos, tecnologias e técnicas que se orientam em direção a normalização - inventada - de um outro - também inventado - como outro deficiente" (SKLIAR, 2011a, p. 125) ${ }^{\mathrm{xi}}$. E, neste sentido, criar um acontecimento educativo visando a experiência, exige do/a educador/a um movimento de desfazer-se de si ao ponto de perder de vista a "egocêntrica normalidade cuja infame tentação é a invenção do anormal" (Skliar, 2011a, p. 123).

Um perder de vista necessário, na educação de modo geral, pois, infelizmente, o paradigma da normalidade está nos olhares, na produção discursiva, nas práticas pedagógicas, na organização das instituições. Deste modo, quando se pensa a educação das pessoas com deficiência, não se pode deixar de problematizar a invenção deste outro "anormal" e as relações de poder e de saber 
aí envolvidas historicamente, bem como, a responsabilidade ética do/a educador/a com cada estudante.

O/A educador/a que deseja a experiência na educação, não se furta da ex-posição do seu corpo, da transmissão dos seus saberes, da possibilidade do não saber e da inteireza do encontro com o outro. Além disso, possibilitar um tempo e espaço para que a experiência ganhe vida, requer do/a educador/a um investimento na condição inexorável do estar sendo dos corpos e na potência de expansão, criação e reinvenção destes e do mundo (GROFF, 2015). Ao mesmo tempo, este investimento necessita de um gesto primeiro de igualdade que, por se contrapor à desigualdade, à hierarquia e à dominação, revela e dá positividade as diferenças que emergem nas relações. Um gesto de igualdade capaz de educar a todos e a qualquer um (SKLIAR, 2011a, 2011b), pois não impõe critérios ou estabelece limites anteriores ao que um encontro com o outro pode produzir. Em outras palavras, "uma gestualidade que reconhece todo e qualquer ser humano como igual, como um ser potente e criador, e que não impõe critérios ou exceções para construção de uma relação educativa" (GROFF, 2015, p. 174).

Contudo, não há como pensar e falar em relações educativas permanecendo apenas no princípio da igualdade. É preciso entender que a igualdade é o que dá abertura para se entrar em relação com o outro como estrangeiro, desconhecido e não como uma imagem tranquila de si mesmo, para que se possa viver aquilo que acontece entre os corpos, seja em conflito, em composição ou reinvenção num acontecimento educativo. Querer a experiência e construir um acontecimento para que ela possa acontecer, exige então uma postura ética do/a educador/a, no sentido de uma relação com o outro que considera "a multiplicidade de corpos em suas espacialidades e temporalidades, para que a diferença que emerge dos encontros entre estes corpos, não se objetive em desigualdades" (GROFF, 2015, p. 174-175).

Por fim, querer a experiência no ensino da música na Educação Especial, exige, por vezes, o abandono das fôrmas da Educação Musical tradicional e até mesmo da musicalidade ocidental, com suas frequências bem definidas e seus ritmos bem marcados. Ou seja, o que se modifica, na composição de um acontecimento educativo, é o próprio saber disciplinar, para que o outro continue permanecendo outro e, ao mesmo tempo, possa se (re)inventar. Para trabalhar com concepções musicais livres, é preciso estar disposto ao destempero sonoro, à aceitação de frequências não usuais, à palavra não ritmada. O desafio do/a educador/a é percebê-las enquanto linguagens da música e desenvolver as propostas inseridas pelos/as educandos/as, colocando a corporeidade dos mesmos em consonância com sua musicalidade e, é claro, dando abertura ao que estes corpos ainda podem. 


\section{Considerações Finais}

O saber produzido pela educadora desde a sua experiência, mostrou que no plano do ensino da música na Educação Especial há um horizonte infinito para a construção de acontecimentos educativos. Não há um modelo a ser seguido, bem como a disposição do/a educador/a e sua responsabilidade ética com o outro não garante de antemão quais serão os resultados. Estes, no campo da criação musical, serão sempre inesperados, pois são contextuais, únicos, dialógicos e perpassados pelas potências singulares e coletivas.

É certo, no entanto, que a composição de acontecimentos educativos por aqueles/as que querem a experiência na educação, precisa estar atravessada por alguns princípios ou dimensões educativas fundamentais: movimentos de paragem que escapem dos automatismos cotidianos; interrupção da normalidade e da normalização do outro; desconstrução de olhares e discursos binários, excludentes, limitadores do que os corpos podem; abandono do prescritivismo, messianismo e finalismo pedagógicos; afirmação da potência criadora do humano; responsabilidade ética com o direito à educação e com a vida do outro.

Ficou claro na produção do trabalho musical com os/as educandos/as que, atualmente, o ensino da música enfrenta o desafio de se consolidar na Educação Básica e em suas modalidades de ensino, principalmente, numa perspectiva que visa processos de criação a partir das potencialidades de cada educando/a e que escape do ensino tradicional desta linguagem artística. O componente vivencial trazido pelos sujeitos a partir de suas relações dentro e fora da instituição foi fundamental no processo criativo, embora seja um aspecto ainda embrionário e ousado no campo específico da Educação Musical, por conta de sua perspectiva predominantemente mais técnica.

Destaca-se também que, para além do que foi vivido em sala de aula, o acontecimento educativo aqui relatado alcançou também os/as profissionais da instituição, as famílias dos/as educandos/as e a comunidade no entorno, pois estes puderam vislumbrar o processo de criação dos/as educandos/as objetivado em um $\mathrm{CD}$, o que gerou novas motivações e perspectivas de relação. Já para os/as educandos/as, não há como traduzir os sentidos de suas experiências, porém, o que se pode aferir a partir da relação da educadora com eles/as, perpassa a evidente alegria e satisfação em se reconhecerem como criadores/as e poderem se identificar com o processo e com as canções que foram gravadas.

Entende-se que o próprio ensino da música tem se constituído, neste sentido, em um processo de criação contextual, singular e de experimentação. Cabe aos/às professores/as de 
música socializarem seus fazeres para que possam (re)inventar os modos de ensinar a linguagem musical para crianças e adolescentes nos múltiplos ambientes em que esta é trabalhada na educação. É necessário e possível (re)pensar as práticas educativas tradicionais, vislumbrando a construção de acontecimentos educativos que possibilitem conexões com as afecções vividas, com as condições de vida dos sujeitos e de seus movimentos de vir a ser.

\section{Referências}

BAKHTIN, M. M. Estética da Criação Verbal. 6. ed. São Paulo: WMF Martins Fontes, 2011.

BEYER, H. O. Educação especial e inclusão: um olhar sobre a história e os paradigmas. In: . Inclusão e avaliação na escola: de alunos com necessidades educacionais especiais. Porto Alegre: Mediação, 2007, p. 11-26.

BRASIL. Decreto $n^{\circ}$ 7.611, de 17 de novembro de 2011. Poder Executivo, Brasília, DF. Disponível em: <http://www.planalto.gov.br/ccivil_03/_ato20112014/2011/decreto/d7611.htm>Acesso em: 14 abr. 2015.

FAÇANHA, T. M. M. A implantação da Lei $n^{o}$ 11.769/2008: uma análise em quatro estabelecimentos da Segunda Unidade SEDUC na Escola, em Belém-Pa. In: IX Encontro Regional Norte da ABEM. Rio Branco, $2014 . \quad$ Disponível em: $<$ http://abemeducacaomusical.com.br/conferencias/index.php/regional_norte/regional_norte/ paper/viewFile/843/317>. Acesso em: 11 abr. 2015.

GROFF, A. R. Entre vozes e linguagens para enunciar a violência: análise dialógica de uma experiência de formação continuada para professores/as. 2015. 270 p. Tese (Doutorado) Universidade Federal de Santa Catarina, Centro de Filosofia e Ciências Humanas, Programa de Pós-Graduação em Psicologia. Florianópolis, 2015.

HENTSCHKE, L.; DEL BEN, L. Aula de música: do planejamento e avaliação à prática educativa. In:___ _ SOUZA, J. (Org.). Avaliação em Música: reflexões e práticas. São Paulo: Editora Moderna, 2003. p. 176-183.

KLEBER, M. O.; PALMA FILHO, J. C. Celeiro de Ideias. Boletim Arte na Escola, São Paulo, v.57, p. 3, 2010. Disponível em:< http://artenaescola.org.br/uploads/boletins/boletim-57.pdf $>$. Acesso em: 11 abr. 2014.

LARROSA, J. Notas sobre a experiência e o saber da experiência. Revista Brasileira de Educação, Rio de Janeiro, n.19, p. 20-28, 2002.

LARROSA, J. Experiencia y alteridad en educación. In: SKLIAR, C.; LARROSA, J. (Org.).Experiencia y alteridad en educación. Rosário: Homo Sapiens Ediciones, 2009. p. 13-44. 
Máscaras, Versos e Risadas. [disco compacto]. Produção Independente. Gaspar 1 disco compacto, 14 min. digital. estéreo, 2010.

ONU. Declaração de Salamanca: sobre princípios, políticas e práticas na área das necessidades educativas especiais. Salamanca, Espanha, 1994. Disponível em: $<$ http://portal.mec.gov.br/seesp/arquivos/pdf/salamanca.pdf >. Acesso em: 16 abr. 2015.

SKLIAR, C. Incluir as diferenças? Sobre um problema mal formulado e uma realidade insuportável. Revista Interinstitucional Artes de Educar, Rio de Janeiro, v. 1, n. 1, p. 13-28, 2015. - Y si el otro no estuviera ahí?Notas para una pedagogía (improbable) de la diferencia.Buenos Aires: Miño y Dávila, 2011a.

. Lo dicho, lo escrito, lo ignorado: Ensayos mínimos entre educación, filosofía y literatura.Buenos Aires: Miño y Dávila, 2011 b.

VEIGA-NETO, A. Educação e Pós-Modernidade: impasses e perspectivas. Aula Inaugural no Programa de Pós-Graduação em Educação da Pontifícia Universidade Católica do Rio de Janeiro (PPG-Educação/PUC-Rio), 2005.Disponível em: http://www.maxwell.vrac.pucrio.br/8708/8708.HTMAcesso em: 10 abr. 2015.

VEIGA-NETO, A.; LOPES, M. C. Inclusão, exclusão, in/exclusão. Verve (PUCSP), v. 1, n. 20, p. 121-135, 2011.

VYGOTSKY, L. S. Psicologia da arte. São Paulo: Martins Fontes, 1999.

WASLAWICK, P. Um encontro musical que engendra um ensemble: a dialogia na música de um duo de violões. In: ZANELLA, A. V.; MAHEIRIE, K. (Org.). Diálogos em Psicologia Social e Arte. Curitiba: Editora CRV, 2010, p.255-274.

SILVA, P. C. Pesquisa sobre o Ensino de Música em Escolas Públicas Municipais do Litoral do Rio Grande do Sul. In: XXVI Salão De Iniciação Científica da UFRGS. Porto Alegre, 2014. Disponível em<http://www.lume.ufrgs.br/handle/10183/113982>. Acesso em: 11 abr. 2015.

ZAMPERETTI, M. P. Estar-junto na sala de aula: inter-relações e reflexões para o ensino da arte. Revista Interinstitucional Artes de Educar, Rio de Janeiro, v. 1, n. 1, p. 80-92, 2015.

ZANELLA, A. V. Sobre olhares, fios e rendas: reflexões sobre o processo de constituição de educadores(as). In: . et al. (Org.). Educação estética e constituição do sujeito: reflexões em curso. Florianópolis: NUP/CED/UFSC, 2007. p. 143-154.

\footnotetext{
${ }^{\text {i }}$ Possui graduação em Psicologia pela Fundação Universidade Regional de Blumenau (2007), mestrado (2010) e doutorado (2015) no Programa de Pós-Graduação em Psicologia da Universidade Federal de Santa Catarina. Atua nos
} 
Núcleos de Pesquisa NUPRA (PPGP) e NUVIC (CED/UFSC). Realizou estágio doutoral na Faculdade Latino Americana de Ciências Sociais (Flacso) em Buenos Aires/Argentina

ii Graduada em Licenciatura em Artes com Habilitação em Música pela FURB Universidade Regional de Blumenau (2009). Especialista em Educação Musical pelo IPGEX Instituto de Pós Graduação e Extensão (2012). Desenvolveu trabalhos em áreas pedagógicas diversas (ensino fundamental e médio, educação de jovens e adultos e educação especial). Agraciada com o PRÊMIO ITAÚ CULTURAL Rumos Educação, Cultura e Arte 2011-2013 pelo projeto Máscaras, Versos e Risadas.

iii Doutoranda em Psicologia no Programa de Pós-Graduação em Psicologia - UFSC. Mestre em Psicologia pelo Programa de Pós-Graduação em Psicologia - UFSC (2014). Formada em Psicologia pela Universidade Regional de Blumenau - FURB (2006). Possui experiência profissional em projetos voltados ao atendimento de crianças e adolescentes, direitos humanos, políticas públicas, educação especial e inclusiva.

${ }^{\mathrm{iv}} \mathrm{O}$ trabalho que resultou na gravação deste CD foi agraciado com o Prêmio Rumos Educação Cultura e Arte 2011-

2013. Deste modo, outros aspectos que o envolvem são públicos, inclusive o $\mathrm{CD}$, e podem ser acessados em: https://www.4shared.com/rar/aKLETs3I/apae _ mscaras_versos_e risada.html.

vAs Instituições de Educação Especial em Santa Catarina respondem à Fundação Catarinense de Educação Especial (FCEE) que é um órgão do governo estadual. Suas diretrizes preconizavam, na época, a formação do SAEDE, sendo os outros programas elaborados por cada instituição a partir de orientações mais gerais. A triagem que direcionava cada educando a um ou outro programa era orientada pelas diretrizes da FCEE e praticada pelos profissionais das áreas da Psicologia, Medicina e Assistência Social atuantes na instituição.

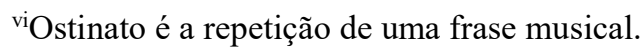

viiLetra da Música "Sobre o Amor", CD "Máscaras, Versos e Risadas".

viiiLetra da Música “Acorda Aparício", CD "Máscaras, Versos e Risadas".

ixLetra da Música "Almir não vá embora”, CD "Máscaras, Versos e Risadas".

“Letra da Música "SPECCOncept", CD “Máscaras, Versos e Risadas”.

${ }^{x i}$ As citações literais de Skliar (2011a) foram traduzidas livremente pelas autoras. 